\title{
PERANCANGAN APLIKASI PERPUSTAKAAN PADA SEKOLAH MENENGAH ATAS NEGERI 6 DEPOK BERBASIS JAVA
}

\author{
Shinta Yulianti \\ Program Studi Teknik Informatika, Fakultas Teknik dan Ilmu Komputer, \\ Universitas Indraprasta PGRI \\ Jalan Raya Tengah No 80, Kelurahan Gedong, Pasar Rebo, Jakarta Timur \\ sintayulianti200@gmail.com
}

\begin{abstract}
Abstrak
Merancang dan mengimplementasikan sistem informasi perpustakaan yang efektif dan efisien pada SMA Negeri 6 Depok. Metodologi penelitian yang digunakan dalam sistem pengolahan data yaitu teknik pengumpulan data seperti observasi, studi dokumentasi, serta melakukan penelitian kepustakaan yang relevan dengan masalah sistem informasi pengolahan data perpustakaan. Metode pengembangan sistem yang digunakan menggunakan metode grounded research. Hasil penelitian ini adalah: Adanya suatu perangkat aplikasi yang dibuat dengan bahasa pemrograman Java NetBeans dan penyimpanan data pada database MySQL dapat memberikan kelancaran dalam pengolahan sistem informasi pada Perpustakaan SMA Negeri 6 Depok.
\end{abstract}

Kata Kunci: Aplikasi, sistem informasi, perpustakaan

\begin{abstract}
Design and implement an effective and efficient library information system at SMA Negeri 6 Depok. The research methodology used in the data processing system is data collection techniques such as observation, documentation studies, and conducting library research that is relevant to the problem of information systems in data processing library. The system development method used uses the grounded research method. The results of this study are: The existence of an application device made with the Java NetBeans programming language and data storage in the MySQL database can provide smooth processing of information systems in the library of SMA Negeri 6 Depok.
\end{abstract}

Key Words: Applications, information systems, libraries

\section{PENDAHULUAN}

Seiring dengan perkembangan teknologi dan informasi yang begitu cepat, sistem informasi memiliki peranan sangat penting bagi suatu organisasi atau perusahaan. Komputer sebagai media pengolah data, apabila dikelola dengan benar akan menjadi sebuah media informasi yang sangat cepat, tepat, dan akurat. Hal ini disebabkan peranan perpustakaan sangatlah penting dalam usaha dan upaya menunjang civitas akademik yang ada pada SMA Negeri 6 Depok, dikarenakan sistem peminjaman dan pengembalian buku pada perpustakaan SMA Negeri 6 Depok masih dilakukan secara manual dari mulai pencatatan data buku, data anggota, peminjaman dan pengembalian buku sampai dengan laporan peminjaman dan pengembalian buku masih secara manual. Kemungkinan pada saat proses sedang berlangsung terjadi kesalahan dalam pencatatan dan keterlambatan dalam pencarian buku. Berdasarkan hal tersebut, maka peneliti menggunakan komputer khusus agar bisa membantu dan mempermudah dalam menyajikan aplikasi tentang peminjaman dan pengembalian buku serta laporan denda (Bafadal 2005).

Untuk merancang sistem informasi perpustakaan peneliti melakukan riset ke perpustakaan untuk mencatat dan cara mengelola perpustakaan agar lebih efisien, dikarenakan banyak terjadi kesalahan pada saat proses peminjaman buku yang dipinjam oleh siswa tidak sesuai dengan buku yang tercatat dalam buku peminjaman. Dan kesalahan pada penelitian nama siswa peminjam, nama siswa tertukar dengan siswa lainnya sehingga saat pencatatan ke dalam peminjaman tertukar, lalu sebagian koleksi buku yang ada di perpustakaan tidak tercatat ke dalam buku peminjaman (Supriyanto 2008).

Tujuan dari penelitian ini antara lain, menetapkan rancangan sistem aplikasi yang sesuai dengan kebutuhan pustakawan dalam mengelola perpustakaan SMA Negeri 6 Depok dan mengelola 
perpustakaan SMA Negeri 6 Depok menjadi tidak manual, yang diharapkan dapat memberikan informasi mengenai laporan yang terperinci, akurat, cepat dan tepat waktu. Dan untuk menyelesaikan permasalahan dan mengembangkan aplikasi perpustakaan SMA Negeri 6 Depok yang sedang berjalan ke dalam bahasa pemrograman java dengan menggunakan database $M y S Q L$ maka sebagai sistem aplikasi perpustakaan yang dapat membantu proses peminjaman, pengembalian dan pencarian buku di SMA Negeri 6 Depok.

\section{PENELITIAN RELEVAN}

Perancangan adalah kumpulan atau group dari sub sistem/ bagian/ komponen apapun baik fisik maupun non fisik yang saling berhubungan satu sama lain dan bekerja sama secara harmonis untuk mencapai satu tujuan tertentu (Susanto 2013). Perancangan adalah proses untuk mendefinisikan sesuatu yang melibatkan deskripsi mengenai arsitektur serta komponen suatu aktivitas rekayasa perangkat lunak.

Pengertian sistem adalah sekelompok unsur yang erat hubungannya dengan yang lain, yang berfungsi bersama-sama untuk mencapai tujuan tertentu. Sistem dapat berupa abstrak atau fisik. Sistem yang abstrak adalah susunan gagasan-gagasan atau konsepsi yang teratur yang saling bergantungan, sedangkan sistem yang bersifat fisik adalah rangkaian unsur yang bekerja sama untuk mencapai suatu tujuan (Sutabri 2012). Sistem adalah rangkaian dari dua atau lebih komponen yang saling berhubungan yang berinteraksi untuk mencapai suatu tujuan, sebagian besar sistem terdiri dari sub sistem yang lebih kecil yang mendukung sistem yang besar (Steinbart 2010). Berdasarkan definisi tersebut, jadi sistem dapat diartikan sebagai suatu sistem yang pada dasarnya memiliki sekelompok unsur/ rangkaian yang erat hubungannya dengan yang lain dan memiliki komponen saling berhubungan untuk mencapai suatu tujuan (Nugraha 2014).

Pengertian Data Flow Diagram (DFD) merupakan penggambaran sistem yang menggunakan bentuk simbol untuk menggambarkan aliran data dalam suatu proses yang saling berhubungan (Bin Ladjamudin 2013). DFD adalah suatu diagram yang menggunakan notasi-notasi untuk menggambarkan arus dari data sistem yang penggunaannya sangat membantu untuk memahami sistem secara logika, terstruktur dan jelas. DFD merupakan alat bantu dalam menggambarkan atau menjelaskan sistem yang sedang berjalan logis (Ladjamudin 2015).

Dari hasil penelitian dan pembahasan yang telah dilakukan terhadap sistem informasi perpustakaan maka didapat suatu kesimpulan sebagai berikut Sistem informasi perpustakaan yang dibuat dapat digunakan untuk memberikan informasi kepada pihak-pihak terkait mengenai bahan pustaka yang dimiliki beserta kondisinya secara akurat dan lengkap serta perkembangan bahan pustaka yang dimiliki. Proses yang yang dilakukan antara lain pendataan buku, pendataan anggota, pencarian bahan pustaka, cetak kartu anggota, cetak surat keterangan bebas perpustakaan, cetak labelisasi buku, transaksi peminjaman maupun transaksi pengembalian buku perpustakaan beserta penerapan denda. Informasi yang dihasilkan meliputi laporan koleksi bahan pustaka, laporan data anggota, laporan transaksi peminjaman dan pengembalian serta laporan penerimaan denda.

Penggunaan aplikasi perpustakaan ini memudahkan serta mempercepat kinerja staff perpustakaan. Staff perpustakaan dapat melakukan pengolahan data perpustakaan dan pembuatan laporan perpustakaan, karena pada aplikasi ini terdapat menu untuk mengolah data koleksi buku, sirkulasi buku, transaksi, data anggota, dan mencetak laporan perpustakaan.

\section{METODE PENELITIAN}

Metode penelitian yang digunakan yaitu metode grounded research. Metode ini adalah suatu metode berdasarkan fakta dan menggunakan analisis perbandingan yang bertujuan untuk generalisasi empiris, menetapkan konsep, membuktikan teori, pengumpulan dan analisis data dalam waktu yang bersamaan (Indrajani 2011). Dalam penelitian grounded research metode yang digunakan adalah studi perbandingan yang bertujuan untuk menentukan seberapa besar suatu gejala tersebut berlaku untuk umum (Afriansyah 2015). Untuk mendapatkan informasi yang dibutuhkan dari objek yang akan diteliti oleh karena itu dilakukan pengamatan langsung di SMA Negeri 6 Depok. 
Metode pengumpulan data merupakan langkah yang paling utama dalam proses penelitian. Adapun metode pengumpulan data yang digunakan pada penelitian ini adalah sebagai berikut:

a. Observasi

Observasi merupakan salah satu cara mengumpulkan data yang diperlukan dengan cara melakukan pengamatan dan meneliti secara langsung gejala atau peristiwa yang diselidiki oleh peneliti. Peneliti melakukan observasi mengenai proses pendaftaran anggota, pembuatan laporan pada perpustakaan SMA Negeri 6 Depok. Metode ini diperlukan untuk mengetahui atau mendapatkan data yang tidak mungkin didapat dengan metode wawancara. Metode observasi ini dilakukan dengan cara melakukan pengamatan secara langsung ke lapangan mengenai pengelolaan data-data perpustakaan.

b. Wawancara

Proses wawancara dilakukan dengan cara tatap muka dan melakukan tanya jawab seputar aktivitas dan yang terjadi di perpustakaan SMA Negeri 6 Depok. Hasil dari wawancara tersebut dikumpulkan dalam bentuk catatan yang kemudian diolah menjadi salah satu sumber informasi. Wawancara merupakan proses memperoleh keterangan untuk tujuan penelitian dengan cara melakukan tanya jawab kepada responden. Dalam melakukan wawancara ini, peneliti melakukan tanya jawab kepada pihak yang terkait, yaitu pengurus perpustakaan dan anggota perpustakaan dengan mengajukan beberapa pertanyaan yang ada kaitannya dengan kebutuhan data yang dikumpulkan oleh peneliti.

c. Studi Pustaka

Pencarian data berupa buku dan referensi tentang pembuatan aplikasi maupun pengertian dari sumber daya manusia itu sendiri. Berupa data berbentuk dokumentasi teks dan pemograman.

\section{HASIL DAN PEMBAHASAN}

Aturan sistem yang diusulkan SMA Negeri 6 Depok pada bagian perpustakaan adalah sebagai berikut:

a. Bagian petugas perpustakaan menerima data dari siswa dan menginputkan seluruh data siswa tersebut pada menu input data anggota perpustakaan.

b. Anggota menerima semua data peminjaman dan denda keterlambatan dari petugas perpustakaan.

c. Kepala sekolah menerima hasil laporan tahunan dari petugas perpustakaan.

Berikut ini merupakan penggambaran tentang sistem yang diusulkan pada SMA Negeri 6 Depok secara keseluruhan dalam bentuk diagram konteks.

\section{Diagram Konteks Sistem yang Diusulkan}

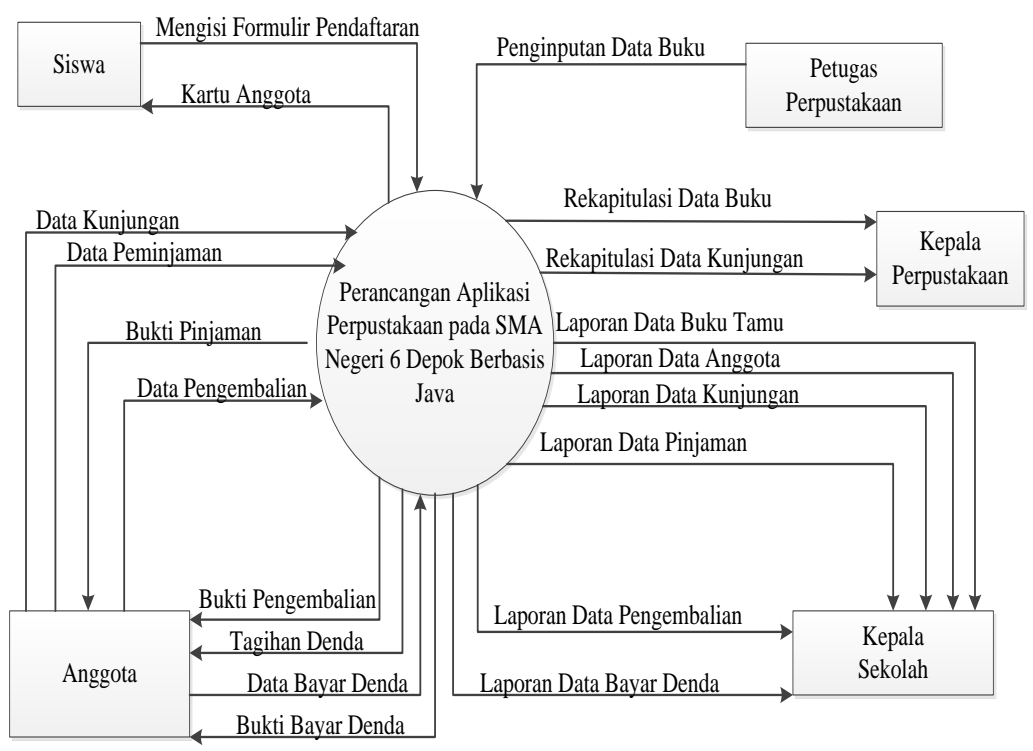

Gambar 1. Diagram Konteks Sistem Yang Diusulkan 


\section{Entity Relationship Diagram (ERD)}

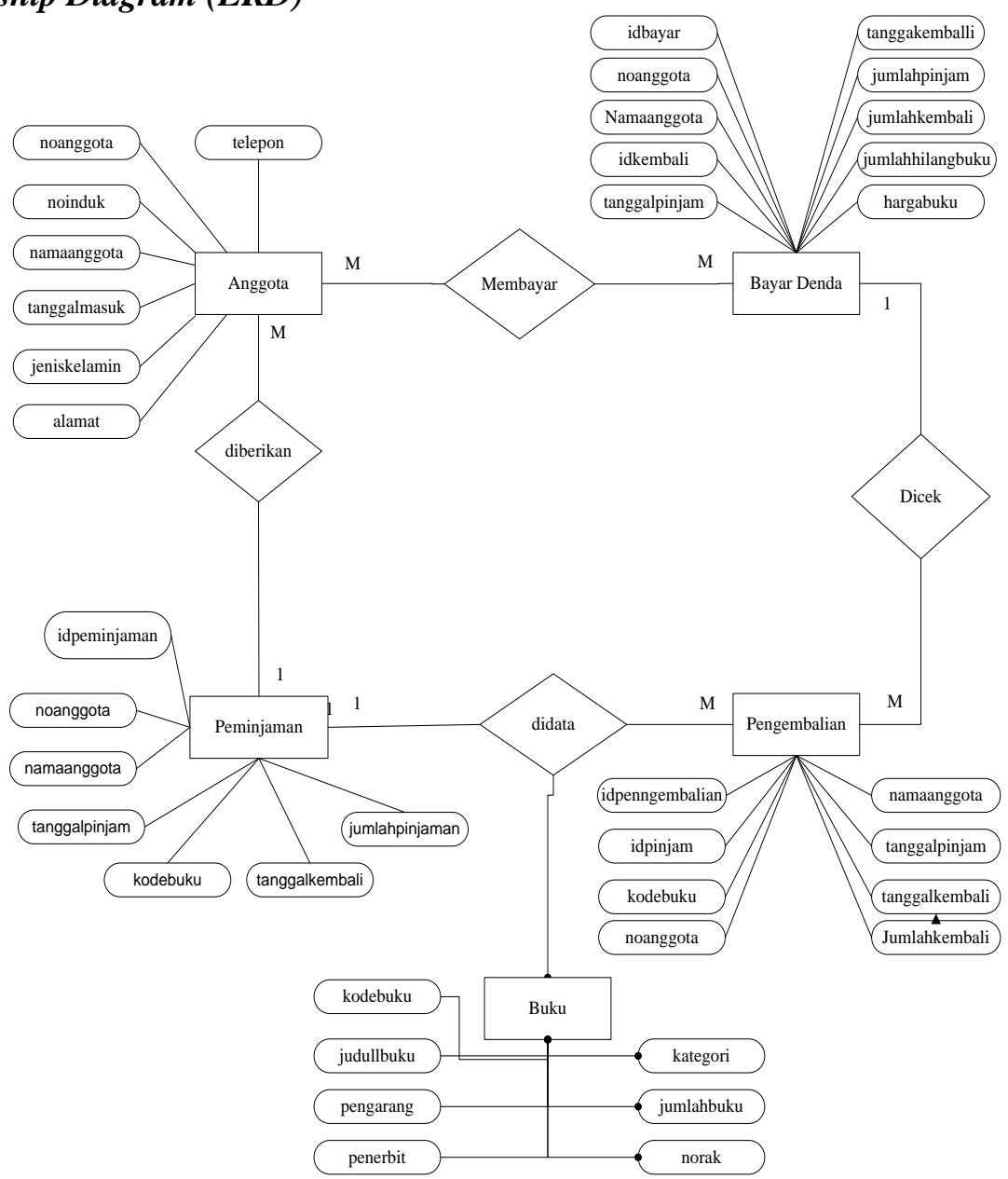

Gambar 2. Entity Relationship Diagram (ERD)

\section{Rancangan Tampilan Layar}

Tampilan Menu Login

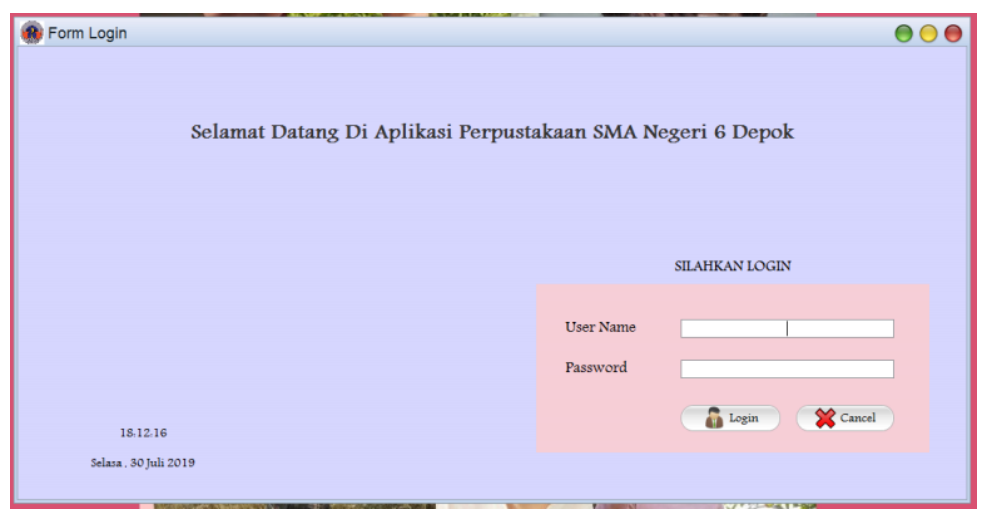

Gambar 3. Tampilan Layar Login

Tampilan ini terdapat pada awal program. Menu login digunakan sebagai kata kunci sebelum kita memasuki program utama. Agar tidak sembarangan orang dapat mengakses program ini. Sehingga dalam Form menu kerahasiaannya tetap terjaga dengan baik. Apabila pengguna dapat memasukkan nama pengguna dan kata kunci dengan tepat, maka menu utama akan tampil dan program siap untuk dijalankan. 


\section{Tampilan Menu Utama}

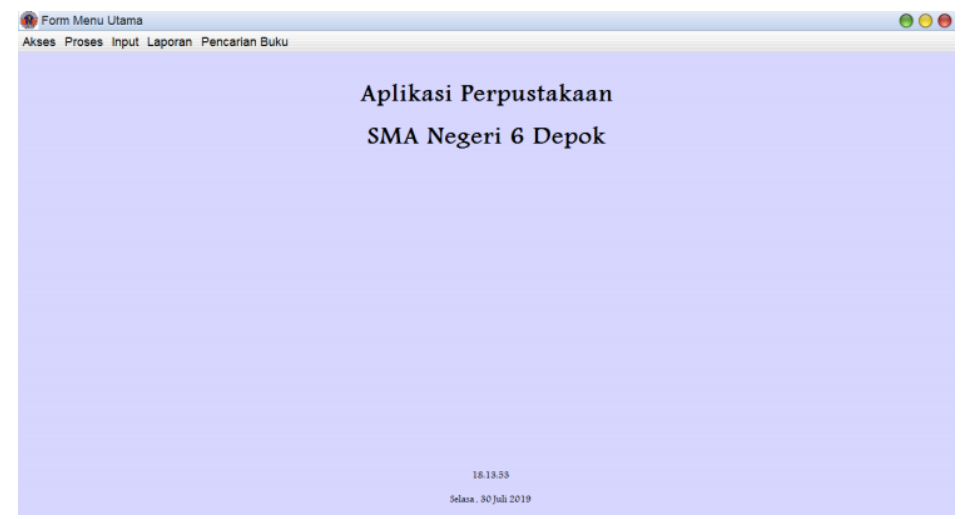

Gambar 4. Tampilan Menu Utama

Layar di atas menampilkan tampilan menu sistem Perpustakaan. Pada layar utama tersedia menu bar yang terdiri dari menu Akses yang digunakan pada saat pengguna ingin login atau exit dari aplikasi, menu berkas yang digunakan untuk memasukkan data yang berkaitan dengan Data Sistem Perpustakaan, menu Input yang digunakan untuk memasukkan data-data Anggota, data-data buku. Menu Laporan untuk mencetak semua laporan sistem Perpustakaan.

\section{Tampilan Data Anggota}

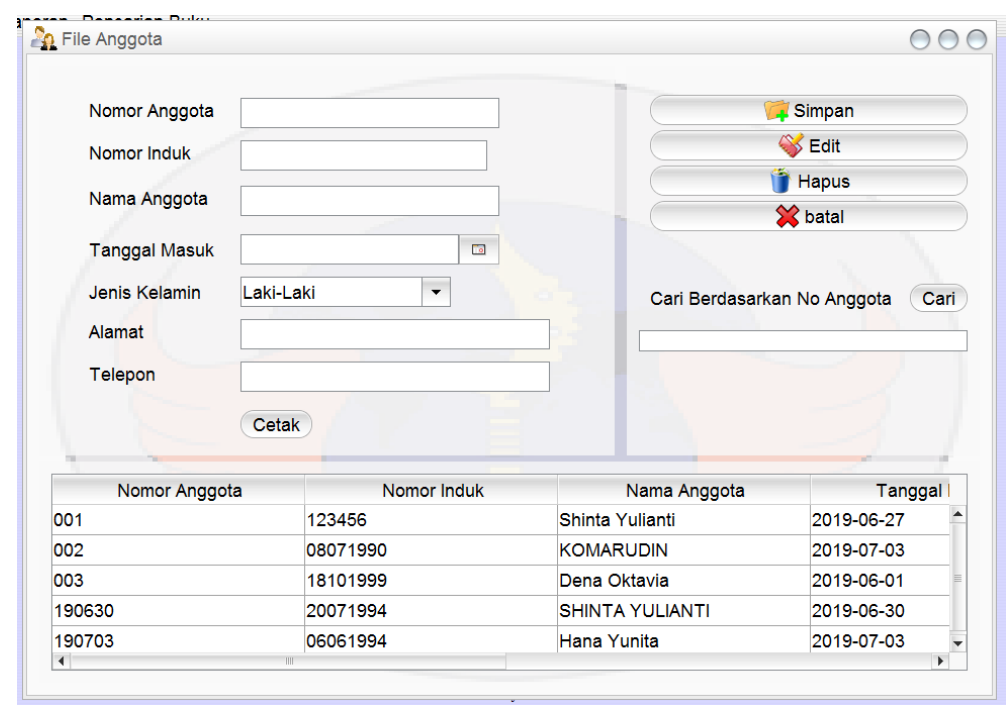

Gambar 5. Tampilan Data Anggota

Pada tampilan diatas merupakan tampilan Form Data Anggota. Form ini memiliki beberapa tombol yang terdiri dari tombol untuk Tambah untuk memasukkan Data Anggota, menyimpan Data Anggota telah di input user cukup menekan tombol Simpan, sedangkan tombol Ubah digunakan untuk mengubah data yang telah di input, tombol Batal digunakan untuk membatalkan semua data yang telah di input, serta tombol Hapus berfungsi ketika user ingin menghapus data yang telah $d i$ input. 


\section{Tampilan Data Peminjaman}

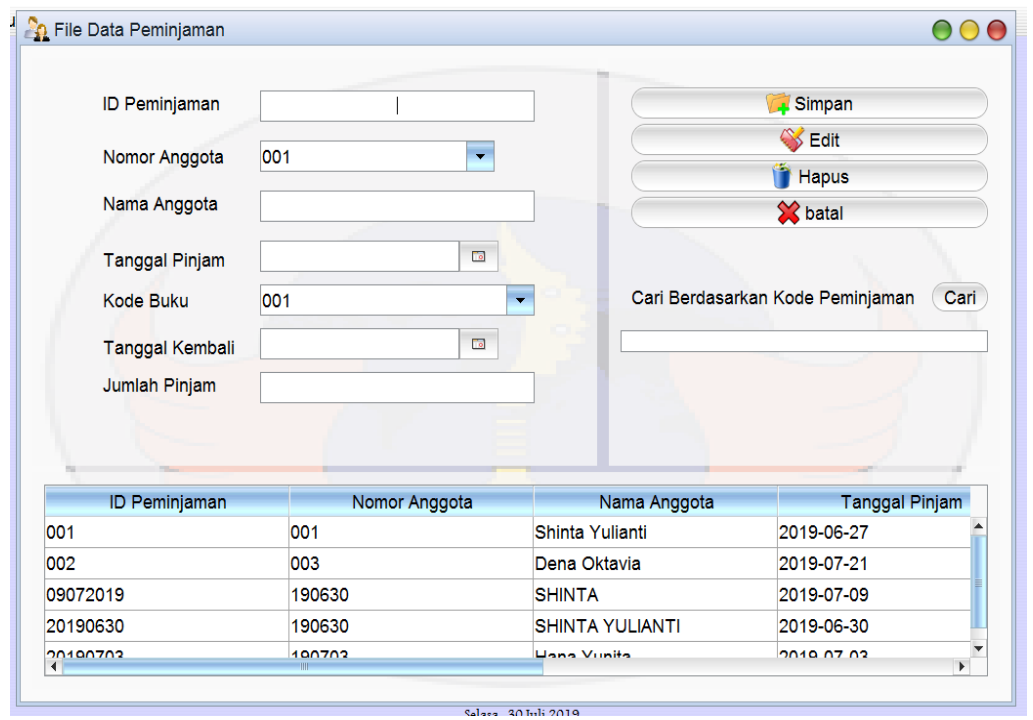

Gambar 6. Tampilan Data Peminjaman

Pada tampilan Form Peminjaman memiliki beberapa tombol yang dapat digunakan untuk menambah, menyimpan, mengubah, membatalkan, dan menghapus semua file Peminjaman yang telah di input. Form ini juga memiliki tombol yang juga digunakan keluar dan kembali ke tampilan menu utama.

\section{Tampilan Data Denda}

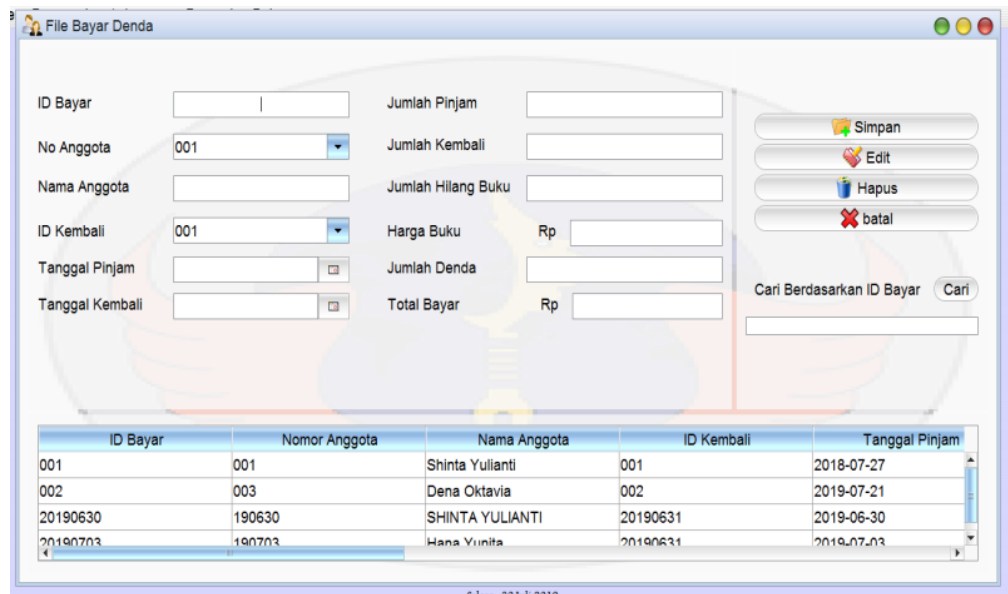

Gambar 7. Tampilan Data Denda

Pada tampilan Form Bayar Denda memiliki beberapa tombol yang dapat digunakan untuk menambah, menyimpan, mengubah, membatalkan, dan menghapus semua file Bayar Denda yang telah di input. Form ini juga memiliki tombol yang juga digunakan keluar dan kembali ke tampilan menu utama. 


\section{Tampilan Laporan Denda}

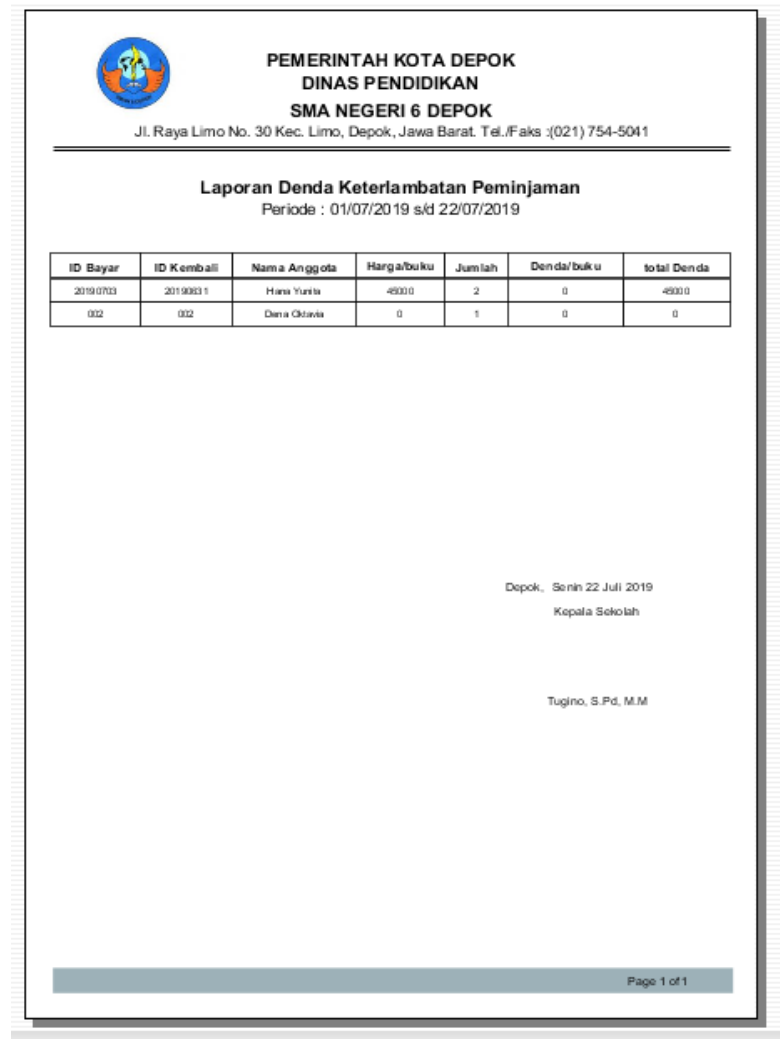

Gambar 8. Tampilan Data Denda

\section{SIMPULAN}

Adapun, kesimpulan yang diperoleh dari Perancangan aplikasi perpustakaan pada Sekolah Menengah Atas Negeri 6 Depok, adalah pengelolaan data buku sudah terkomputerisasi, dengan aplikasi ini maka keakuratan data peminjaman buku lebih optimal dan efisien, dengan adanya aplikasi ini penyimpanan data peminjaman di SMA Negeri 6 Depok jauh lebih baik dan tidak membutuhkan waktu yang lama dalam melakukan pencarian data, dengan diterapkan aplikasi perpustakaan di SMA Negeri 6 Depok ini merupakan salah satu langkah maju dalam penerapan teknologi informasi, aplikasi perpustakaan yang dibuat hanya sebagai penunjang proses peminjaman buku untuk mengefisienkan waktu dan keamanan data yang setidaknya dapat membantu bagian perpustakaan dalam proses peminjaman buku di perpustakaan SMA Negeri 6 Depok.

\section{DAFTAR PUSTAKA}

Afriansyah, Aidil. 2015. “Analisa Dan Perancangan Aplikasi Perpustakaan Menggunakan Java.” Jakarta: Politeknik Sekayu.

Bafadal. 2005. "Pengelolaan Perpustakaan Sekolah.” Jakarta: Bumi Aksara.

Indrajani. 2011. "Perancangan Basis Data Dalam All in 1." Jakarta: Andi.

Ladjamudin, Al-Bahra. 2015. "Data Flow Diagram." Yogyakarta: Graha Ilmu.

Bin Ladjamudin. 2013. "Data Flow Diagram." Pp. 1689-99 in Analisis dan Desain Sistem Informasi. Vol. 53. Yogyakarta: Graha Ilmu.

Nugraha, Fajar. 2014. "Analisa Dan Perancangan Sistem Informasi Perpustakaan." Yogyakarta: Elex Media Komputerindo.

Steinbart, Paul John. 2010. "Pengertian Sistem.” Prentice Hall.

Supriyanto, Wahyu. 2008. "Teknologi Informasi Perpustakaan.” Yogyakarta: Kanisius.

Susanto, Azhar. 2013. "Pengertian Perancangan.” Jakarta: Kencana Prenada Media Group.

Sutabri, Tata. 2012. "Analisis Sistem Informasi." Yogyakarta: Andi. 